\title{
Genetic parameters for direct and maternal calving ease in Walloon dairy cattle based on linear and threshold models
}

\author{
S. Vanderick ${ }^{1}$, T. Troch $^{1}$, A. Gillon ${ }^{1,2}$, G. Glorieux ${ }^{2}$ \& N. Gengler ${ }^{1}$ \\ 1 Animal Science Unit, Gembloux Agro-Bio Tech, University of Liège, Gembloux, Belgium \\ 2 Research and Development Department, Walloon Breeding Association, Ciney, Belgium
}

\author{
Keywords \\ Animal model; dystocia; heritability; holstein.

\section{Correspondence} \\ S. Vanderick, Animal Science and Nutrition \\ Unit, Gembloux Agro-Bio Tech (GXABT), \\ University of Liege, Passage des Déportés, \\ 2, Gembloux B-5030, Belgium. \\ Tel: +3281622351 ; \\ Fax: +3281622115 ; \\ E-mail: sylvie.vanderick@ulg.ac.be
}

Received: 18 July 2013;

accepted: 2 June 2014

\section{Summary}

Calving ease scores from Holstein dairy cattle in the Walloon Region of Belgium were analysed using univariate linear and threshold animal models. Variance components and derived genetic parameters were estimated from a data set including 33155 calving records. Included in the models were season, herd and sex of calf $\times$ age of dam classes $\times$ group of calvings interaction as fixed effects, herd $\times$ year of calving, maternal permanent environment and animal direct and maternal additive genetic as random effects. Models were fitted with the genetic correlation between direct and maternal additive genetic effects either estimated or constrained to zero. Direct heritability for calving ease was approximately $8 \%$ with linear models and approximately $12 \%$ with threshold models. Maternal heritabilities were approximately 2 and 4\%, respectively. Genetic correlation between direct and maternal additive effects was found to be not significantly different from zero. Models were compared in terms of goodness of fit and predictive ability. Criteria of comparison such as mean squared error, correlation between observed and predicted calving ease scores as well as between estimated breeding values were estimated from 85118 calving records. The results provided few differences between linear and threshold models even though correlations between estimated breeding values from subsets of data for sires with progeny from linear model were 17 and $23 \%$ greater for direct and maternal genetic effects, respectively, than from threshold model. For the purpose of genetic evaluation for calving ease in Walloon Holstein dairy cattle, the linear animal model without covariance between direct and maternal additive effects was found to be the best choice.

\section{Introduction}

All dairy cows must give birth to begin producing milk. In most cases, calving proceeds normally but problems may happen before or during the calving and cause various problems. The major problem is dystocia which may be defined as calving difficulty resulting from prolonged spontaneous calving or prolonged or severe assisted extraction. Mee (2008) provides a good review of the different types of dystocia and their associated risk factors in dairy cattle. Calving complications impact production, fertility, and cow and calf morbidity and mortality and thus can negatively affect economic profitability in dairy herds (Dekkers 1994; Dematawena \& Berger 1997; López de Maturana et al. 2007b; Eaglen et al. 2011). Calving-related infections affect also indirectly human health as they require increased use of antibiotics, leading potentially to microbial resistance. Besides, animal welfare is compromised by these calving complications and so consumer acceptability of dairy production systems (Mee 2008). 
Calving ease measures the presence or absence of dystocia and its intensity. This trait is generally scored on a categorical scale by the breeder, which makes it more sensitive to subjectivity (Dekkers 1994). Furthermore, this trait is affected by two additive genetic components, the calf's contribution (direct effect; e.g. arising from size, birthweight, hormonal balance...) and the dam's contribution (maternal effect; e.g. arising from pelvic opening, uterine influence of the dam on her calf's birthweight...). The direct additive effect is expressed only once, when the calf is born, whereas the maternal additive effect is expressed several times, each time a cow calves.

From a theoretical point of view, threshold models are preferred over linear models as a method for genetic analysis of such categorical traits displaying a discrete probability distribution (Gianola 1982), and this was confirmed with simulated data by Hoeschele (1988). However, several studies in sheep, beef and dairy cattle using field data found no clear advantage of threshold over linear models (Weller \& Gianola 1989; Olesen et al. 1994; Matos et al. 1997; Varona et al. 1999; Ramirez-Valverde et al. 2001; Phocas \& Laloë 2003). Some of these studies reported greater computational requirements with threshold than with linear models. This might explain why most of the routine genetic evaluations of categorical calving traits are based on linear models (Interbull 2013), although such data violate the assumption of normality. Calving traits are evaluated with a threshold approach only in France, Italy and the USA (Ducrocq 2000; Canavesi et al. 2003; Wiggans et al. 2003).

Models used for routine genetic evaluation of calving ease range from sire (-maternal grandsire) models to animal models in univariate or multitrait form that either allow a covariance between direct and maternal genetic effects or fix this covariance to zero (Interbull 2013). Many threshold models are implemented as models with sire-maternal grandsire effects to avoid convergence problems and biased estimation of genetic parameters due to the well-known extreme category problem, particularly in the presence of numerous fixed effect classes (Luo et al. 2001). However, because some cows with calving records that also have their own direct calving records as a calf, an animal model seems more appropriate to include information on the cows themselves and so generates directly breeding values for direct and maternal effects for bulls and cows.

The purpose of this research was to compare linear and threshold animal models for the prediction of breeding values for calving ease and to estimate the genetic parameters for direct and maternal additive effects for calving ease in the Walloon Holstein dairy cattle. Models were compared on the basis of their predictive abilities to determine the most suitable model for current Walloon data.

\section{Materials and methods}

\section{Data}

In the Walloon Region of Belgium, calving ease is scored by dairy breeders on a voluntary basis and collected by the Walloon Breeding Association (AWE). Calving ease scores range from 1 to 4 (1. Caesarean and embryotomy, 2 . hard pull, 3 . easy pull and 4 . normal). The original data set comprised 138144 calving records and presented a typical distribution of calving ease; most of the records fell into category 4 (69\%) and few records into category 1 (approximately $1 \%$ ). From this original data set, two data sets were created, one for the (co)variance components estimation (data set I) and one for the validation/comparison of models (data set II). Records from Holstein calves born between 2000 and 2012 were used for this research, and data editing was almost identical for both data sets.

Data were edited to remove all suspect records, which included records with out-of-range values for calving ease or missing information related to the factors in the statistical model, including animal identification, birth date, herd identification, calving date, parity number, calving scores and sex of calf. Only records on single born calves were used. Records were limited to first five parities. Calving age of dams was restricted to be between 21 and 48 months for primiparous (1st parity) cows and between 31 and 142 months for multiparous (2nd to 5th parities) cows. Percentage of records for dams outside these ages was relatively small $(<0.2 \%)$. Data quality depends highly on dairy breeders' own judgement to assign scores for calving ease. Therefore, only herds with a standard deviation for scores $>0.05$ were kept to avoid herds where breeders put all scores in the same category. In addition to all the general edits, some specific edits were applied to each data set.

For the data set I, all calves had to have sire and dam identified and every dam had to have a calving record in first parity. Herds displaying less than four first calvings on average per year were deleted. In each herd, only data from continuous calvings per dam were kept (e.g. if a dam displayed records from its first, second and fourth calvings, only records from first and second calvings were kept). A final edit required on average more than one calving per dam 
per herd. The objective was to create a reliable data set without unnecessarily reducing the available data. The final data set I included records from 33155 calves born in 492 Walloon herds from 2215 sires, 25240 dams and 2031 maternal grandsires. The total number of animals including ancestors without records was 120374 .

For the data set II, all calves had to have only dam identified and herds had to display at least, on average, four calvings per year calculated from the first two parities. The final data set II included records from 85118 calves originating from 862 Walloon herds, from 3148 sires, 62265 dams and 3352 maternal grandsires. The total number of animals in the pedigree was 233882 .

For both data sets, calving ages of dam were divided into eleven classes: 21-24, 25-26, 27-28, 29-30, 31$35,36-38,39-48,49-56,57-65,66-81$ and more than 81 months at calving. Calving seasons were divided into four seasons: winter season from January to March, spring season from April to June, summer season from July to September and autumn season from October to December.

\section{Models of analysis}

All the fitted models included the three following fixed effects: season effects, herd effects and combined effects of sex of calf by age of dam classes by group of parities (two groups: first parity and the 2nd to the 5 th parity).

\section{Univariate linear animal model}

Calving ease was modelled as a continuous trait:

$$
\mathbf{y}_{\mathrm{CE}}=\mathbf{X} \beta+\mathbf{Z}_{\mathbf{h}} \mathbf{h}+\mathbf{z}_{\mathbf{a}} \mathbf{a}+\mathbf{Z}_{\mathbf{m}} \mathbf{m}+\mathbf{z}_{\mathbf{p}} \mathbf{p}+\mathbf{e}
$$

where $\mathbf{y}_{\mathrm{CE}}$ is a vector of observed calving ease scores, $\boldsymbol{\beta}$ is a vector of fixed effects, $\mathbf{h}$ is a vector of random herd $\times$ year of calving effects which were included to account for the variability in the frequency of dystocia among herds and years within herds, $\mathbf{a}$ is a vector of random direct additive genetic effects, $\mathbf{m}$ is a vector of random maternal additive genetic effects, $\mathbf{p}$ is a vector of random permanent maternal environmental effects; $\mathbf{X}, \mathbf{Z}_{\mathrm{h}}, \mathbf{Z}_{\mathrm{a}}, \mathbf{Z}_{\mathrm{m}}$ and $\mathbf{Z}_{\mathrm{p}}$ are incidences matrices linking observations with respective effects; $\mathbf{e}$ is a vector of residual effects. There might be some statistical problems and convergence issues with the estimation of fixed herd $x$ year of calving with a threshold model when dealing with herd $\times$ year of small size or with some scores not registered (i.e. the extreme category problem). A random herd $\times$ year effect was fitted to avoid this problem (Misztal et al. 1989). Even if this issue is less a problem in linear models, the same random herd $\times$ year effect was kept.

Model indicated as Model Ll was fitted with an estimated genetic correlation between direct and maternal additive genetic effects. Model indicated as Model L2 was fitted with a genetic correlation between genetic effects constrained to zero.

\section{Univariate threshold animal model}

The same fixed and random effects as in the linear model were considered, but this model assumed the existence of a latent or underlying unobservable normal variable - that is, a liability $(L)$ - modelling the response of calving ease with the following distribution:

$$
\begin{gathered}
f\left(y_{\mathrm{CE}} \mid L\right)=\prod_{i=1}^{\mathrm{n}} f\left(y_{\mathrm{CE}} \mid L_{i}\right)=\prod_{i=1}^{\mathrm{n}}\left[I\left(L_{i}<t_{1}\right) I\left(y_{\mathrm{CE}_{i}}=1\right)\right. \\
+I\left(t_{1}<L_{i}<t_{2}\right) I\left(y_{\mathrm{CE}_{i}}=2\right) \\
+I\left(t_{2}<L_{i}<t_{3}\right) I\left(y_{\mathrm{CE}_{i}}=3\right) \\
\left.+I\left(L_{i}>t_{3}\right) I\left(y_{\mathrm{CE}_{i}}=4\right)\right]
\end{gathered}
$$

where $\mathbf{y}_{\mathrm{CE}}$ are the observed calving ease scores, $t_{1}, t_{2}$ and $t_{3}$ are thresholds that categorize the four categories of response and $I$ is an indicator function that takes value 1 if the condition specified is true and 0 otherwise. A response in a given category is observed, if the actual value of liability falls between the thresholds defining the appropriate category.

Just as Wang et al. (1997), thresholds $t_{1}$ and $t_{2}$ were assumed to be known and $t_{3}$ was assumed to be unknown in order to simplify the sampling scheme rather than the one defined by setting the residual variance of the categorical trait to one. Therefore, the values of $t_{1}$ and $t_{2}$ were based on the observed frequencies of calving ease scores in the considered categories, and residual variance was assumed to be unknown.

Model indicated as Model Tl was fitted with an estimated genetic correlation between direct and maternal additive genetic effects. Model indicated as Model T2 was fitted with a genetic correlation between genetic effects constrained to zero.

Variance components were estimated based on the data set I, for the four models by a Bayesian approach using the Gibbs sampling algorithm with flat priors for (co) variances. Gibbs sampling was used to obtain the marginal posterior distribution for variance components of each random effect from the model from 400000 samples, after discarding 50000 samples as the burn-in period. The stationary stage was confirmed by graphical inspection of plots of sampled values versus iterations. Every fifth sample was 
retained to compute mean and standard deviation of the marginal posterior distribution. The estimation and the post-Gibbs analysis were performed using programs kindly provided by Ignacy Misztal (Misztal et al. 2002).

\section{Comparison of models}

Models were compared on their goodness of fit but also on their ability to predict 'future data'. For this purpose, the entire data set II was split into two parts. One-half of the calving ease records was randomly set to missing in the first data subset and the remaining one-half was set to missing in the second data subset. So, each calving ease record was only present in one of the two subsets. For these two subsets, direct and maternal breeding values and expectations of calving ease score were computed with a BLUP approach for linear and threshold models. This strategy was repeated five times to get ten subsets, that is, five paired subsets.

Within each model and for each of the ten data subsets, mean square errors (MSEs) were computed between expectations from the predictive distribution and the observed calving ease records which had been randomly set to missing.

The MSE was defined for linear model as:

$$
\mathrm{MSE}=\frac{\mathrm{l}}{\mathrm{n}} \sum_{i=1}^{\mathrm{n}}\left(y_{\mathrm{CE} i}-\hat{y}_{\mathrm{CE} i}\right)^{2}
$$

where $y_{\mathrm{CE}}$ and $\hat{y}_{\mathrm{CE}}$ correspond to the observed and predicted calving ease scores, respectively; $\mathrm{n}$ is the number of data points in a data subset.

With the threshold model, MSE was computed, based on López de Maturana et al. (2009) as:

$$
\mathrm{MSE}=\frac{1}{\mathrm{n}} \sum_{i=1}^{\mathrm{n}}\left(y_{\mathrm{CE} i}-\sum_{C=1}^{\mathrm{ncat}} C \times P_{C i}\right)^{2}
$$

where the probability $\left(P_{C i}\right)$ that observation $i$ falls in category $C$ was computed as:

$$
P_{C i}=\Phi\left(\frac{t_{C}-L_{\mathrm{CE} i}}{\hat{\sigma}_{e}}\right)-\Phi\left(\frac{t_{C-1}-L_{\mathrm{CE} i}}{\hat{\sigma}_{e}}\right)
$$

with $\Phi$ (.) is the cumulative distribution function of a normal variable evaluated at (.); $t_{\mathrm{C}}$ is the inferred value of the appropriate threshold, and $L_{\mathrm{CE} i}$ is the posterior mean of the liability to calving ease for an individual $i$.

Within each model and for each of the ten data subsets, Pearson's correlation between observed and predicted scores was calculated as:

$$
r\left(y_{\mathrm{CE}}, \hat{y}_{\mathrm{CE}}\right)=\frac{\operatorname{cov}\left(y_{\mathrm{CE}}, \hat{y}_{\mathrm{CE}}\right)}{\sigma_{y_{\mathrm{CE}}} \sigma_{\hat{y}_{\mathrm{CE}}}}
$$

where $\operatorname{COV}\left(y_{\mathrm{CE}}, \hat{y}_{\mathrm{CE}}\right)$ is the estimate of covariance between the observed and predicted calving ease scores, and $\sigma_{y_{\mathrm{CE}}}$ and $\sigma_{\hat{y}_{\mathrm{CE}}}$ are the estimates of standard deviations of observed and predicted calving ease scores, respectively.

Three groups of sires with progeny were created depending on their accuracy as follows: low: sires $>0 \leq 50$ progeny, medium: sires $>50 \leq 100$ progeny and high: sires $>100$ progeny. For each of these three groups of sires, correlations between sire breeding values were calculated for each of the five paired data subsets within each model to assess model prediction performance. A higher correlation estimate implied a better stability of the model to predict breeding values for animals whose records were randomly set to missing.

Finally, Spearman's rank correlations were computed between sire breeding values estimated from linear model and from threshold model for sires with progeny.

\section{Results and discussion}

The descriptive statistics of the data set I and data set II are displayed in Table 1. Disproportionate sex ratios were observed in records, and there were fewer male calves than female calves in both data sets. Further investigation suggested there may be a bias in recording of the sex of the calf as some breeders prefer to record female calves than male calves due to the difference in value between a male and a female calf in dairy cattle. This recording bias in the number of female and male calves can lead to an underreporting of difficulty to calve (score $<4$ ) because the calving of male calves is known to be more difficult (Mee 2008).

\section{(Co)Variance components and derived genetic parameters}

Results for the (co)variance components and derived genetic parameters are reported in Table 2. Parameters generally were significantly different from zero because posterior means were more than two posterior standard deviations from zero, except for genetic correlation between direct and maternal additive genetic effects for Model Ll and Model Tl (i.e. models fitted with an estimated genetic correlation). 
Table 1 Summary of edited data set used to estimate (co)variance components (data set I) and edited data set used for validation of models (data set II)

\begin{tabular}{|c|c|c|c|c|}
\hline \multirow[b]{2}{*}{ Item } & \multicolumn{2}{|l|}{ Data set I } & \multicolumn{2}{|l|}{ Data set II } \\
\hline & $\begin{array}{l}\text { No. of } \\
\text { observations }\end{array}$ & Percentage & $\begin{array}{l}\text { No. of } \\
\text { observations }\end{array}$ & Percentage \\
\hline Final data file & 33155 & - & 85118 & - \\
\hline Female calves & 26177 & 78.9 & 66511 & 78.1 \\
\hline Male calves & 6978 & 21.1 & 18511 & 21.9 \\
\hline Final pedigree file & 120374 & - & 233882 & - \\
\hline Herds & 492 & - & 862 & - \\
\hline Sires with progeny records & 2215 & - & 3148 & - \\
\hline$>0 \leq 50$ progeny & 2067 & - & 2785 & - \\
\hline$>50 \leq 100$ progeny & 90 & - & 180 & - \\
\hline$>100$ progeny & 58 & - & 183 & - \\
\hline Dams & 25240 & - & 62265 & - \\
\hline $\begin{array}{l}\text { Maternal grandsires } \\
\text { Calving ease }\end{array}$ & 2031 & - & 3352 & - \\
\hline $\begin{array}{l}\text { 1. Caesarean and } \\
\text { embryotomy }\end{array}$ & 443 & 1.3 & 781 & 0.9 \\
\hline 2. Hard pull & 2179 & 6.6 & 4006 & 4.7 \\
\hline 3. Easy pull & 10114 & 30.5 & 23461 & 27.6 \\
\hline 4. Normal & 20419 & 61.6 & 56870 & 66.8 \\
\hline
\end{tabular}

Table 2 Posterior mean (PM) and posterior standard deviation (PSD) of (co)variance components and related genetic parameters estimated with each of four models

\begin{tabular}{|c|c|c|c|c|c|c|c|c|}
\hline \multirow[b]{2}{*}{ Parameter $^{\mathrm{b}}$} & \multicolumn{2}{|c|}{ Model L $1^{\mathrm{a}}$} & \multicolumn{2}{|c|}{ Model L2 ${ }^{\mathrm{a}}$} & \multicolumn{2}{|c|}{ Model T1 ${ }^{\mathrm{a}}$} & \multicolumn{2}{|c|}{ Model T2 } \\
\hline & PM & PSD & PM & PSD & PM & PSD & PM & PSD \\
\hline$\sigma_{h}^{2}$ & 0.042 & 0.002 & 0.042 & 0.002 & 0.146 & .012 & 0.146 & 0.012 \\
\hline$\sigma_{a}^{2}$ & 0.027 & 0.004 & 0.028 & 0.004 & 0.085 & 0.015 & 0.082 & 0.013 \\
\hline$\sigma_{m}^{2}$ & 0.008 & 0.003 & 0.009 & 0.002 & 0.027 & 0.008 & 0.024 & 0.008 \\
\hline$\sigma_{p}^{2}$ & 0.018 & 0.004 & 0.017 & 0.005 & 0.035 & 0.012 & 0.034 & 0.010 \\
\hline$\sigma_{e}^{2}$ & 0.269 & 0.005 & 0.269 & 0.005 & 0.411 & 0.049 & 0.413 & 0.048 \\
\hline$r_{u}(a, m)$ & 0.088 & 0.194 & - & - & -0.071 & 0.190 & - & - \\
\hline$h_{a}^{2}$ & 0.074 & 0.012 & .078 & .012 & 0.121 & 0.024 & 0.117 & 0.020 \\
\hline$h_{m}^{2}$ & 0.023 & 0.007 & .024 & .007 & 0.039 & 0.012 & 0.034 & 0.011 \\
\hline$c_{h}$ & $12 \%$ & & $12 \%$ & & $21 \%$ & & $21 \%$ & \\
\hline$C_{p}$ & $5 \%$ & & $5 \%$ & & $5 \%$ & & $5 \%$ & \\
\hline$C_{e}$ & $74 \%$ & & $74 \%$ & & $59 \%$ & & $59 \%$ & \\
\hline
\end{tabular}

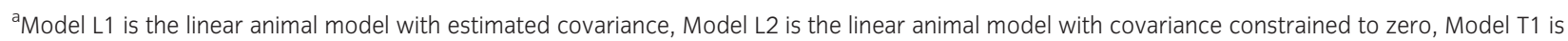
the threshold animal model with estimated covariance, and Model T2 is the threshold animal model with covariance constrained to zero.

${ }^{\mathrm{b}}$ The terms $\sigma_{h}^{2}$ is the herd $\times$ year of calving variance, $\sigma_{a}^{2}$ is the direct additive genetic variance, $\sigma_{m}^{2}$ is the maternal additive genetic variance, $\sigma_{p}^{2}$ is the permanent maternal environmental variance, $\sigma_{e}^{2}$ is the residual variance, $r_{u}(a, m)$ is the genetic correlation between direct and maternal effects, $h_{a}^{2}$ and $h_{m}^{2}$ are the direct and the maternal heritabilities, respectively. $C_{h}, C_{p}$ and $C_{e}$ are the herd $x$ year of calving fraction, permanent maternal environmental fraction and residual fraction in the phenotypic variance, respectively.

The additive genetic variance due to direct effects was greater than that due to maternal effects for all models. On average, direct heritabilities were approximately three to four times as large as maternal heritabilities. All heritabilities estimated with all models were within the range of previously published estimates of this trait in dairy cattle, which ranged from 0.03 to 0.17 for direct heritability and from 0.02 to 0.12 for maternal heritability (Weller $\&$ Gianola 1989; Steinbock et al. 2003; Wiggans et al. 2003; López de
Maturana et al. 2007a; Eaglen et al. 2012). These estimates are not directly comparable because of different models (animal versus sire and maternal grandsire, linear versus threshold, univariate versus bivariate) that were used. However, most previous estimates tended to show that direct heritability was greater than maternal heritability.

Effects of herd $x$ year of calving represent differences among herds and years of calving, which can be partly due to differences in subjective scoring of 
calving ease. Fitting herd $\times$ year effects as random allows more effective use of the data when applying the threshold model. The herd $\times$ year of calving effects represented 12 and $21 \%$ of the phenotypic variance for the linear and threshold models, respectively, which was the largest contributor to the phenotypic variance after the residual effects (74 and $59 \%)$.

The maternal permanent environment effects represented $5 \%$ of the phenotypic variance in each model and were greater than the genetic maternal effects. Preliminary analyses based on the current data showed that maternal genetic variances tended to be overestimated by models that ignored permanent environmental effects.

Estimates of variance components and derived genetic parameters were similar within model type (linear versus threshold). A positive genetic correlation was found with Model Ll and a negative one with Model Tl, but in both cases, the genetic correlation was not significant. Therefore, it seemed more appropriate to consider no genetic correlation between direct and maternal additive genetic effects in the subsequent stage of this study.

The analysis of calving ease with linear models yielded variance estimates that were consistently smaller than those obtained with threshold models. Particularly, variance of herd $\times$ year of calving effects showed a marked decrease from threshold models to linear models. Threshold model heritability estimates were greater than linear model heritability estimates (0.117 versus 0.078 and 0.034 versus 0.024 for direct and maternal heritabilities, respectively), but these heritabilities cannot be directly compared because they were estimated on different scales, on a visible probability scale and on an underlying normal scale for linear and threshold models, respectively. Furthermore, heritability estimates are frequency dependent when a linear model is used to fit categorical traits. Dempster \& Lerner (1950) proposed transformations to make heritabilities comparable. As reported by several studies, higher heritabilities are usually expected with threshold models than linear models (Luo et al. 1999; Phocas \& Laloë 2003).

The best fit of the model, measured by the percentage of residual variance in the phenotypic variance, was achieved for threshold models, approximately $59 \%$ against $74 \%$ with linear models.

\section{Comparison of models}

The MSE for Model L2 and Model T2 used to predict the calving ease records set to missing in the ten data subsets is provided in Table 3. Models with the smaller MSE had better predictive ability. In general, MSE was similar for both models with only very small differences. Based on the average MSE, the threshold model did not perform better than linear model (0.294 versus 0.293$)$. These results were consistent with those obtained by Varona et al. (1999) who also used differences in MSE as a criterion for comparison of models. They found small differences between univariate linear and threshold models based on field and simulated data in beef cattle.

Table 3 also displays Pearson's correlation estimates between observed and predicted calving ease scores by Models L2 and T2 for the ten subsets. Similar to MSE, differences in correlation between models were very small. For all subsets, the threshold model performed slightly better than the linear model $(0.502$ versus 0.497 ). These results were expected because the threshold model is considered as being strategy better model to fit such categorical traits.

Table 4 contains the average correlation estimates between the five paired data subsets for genetic direct and maternal calving ease breeding values from Models L2 and T2 considering sires with 50 or fewer progeny (low-accuracy sires), sires with between 51 and 100 progeny (medium-accuracy sires) and sires with more than 100 progeny (high-accuracy sires). The differences between linear and threshold models decreased as the number of progeny records available for sires increased, especially for differences between sire breeding values for maternal effects. So, if the number of calving records per sire is limited,

Table 3 Mean squared error (MSE) and Pearson's correlation estimates between observed and predicted calving ease scores for Model L2 and Model T2 for the ten replicates

\begin{tabular}{llllll}
\hline & \multicolumn{2}{l}{ MSE } & & \multicolumn{2}{l}{ Correlation } \\
\cline { 2 - 3 } \cline { 5 - 6 } Subset & Model L2 $^{\mathrm{a}}$ & Model T2 $^{\mathrm{a}}$ & & Model L2 $^{\mathrm{a}}$ & Model T2 $^{\mathrm{a}}$ \\
\hline 1 & 0.292 & 0.292 & & 0.497 & 0.502 \\
2 & 0.296 & 0.297 & & 0.493 & 0.497 \\
3 & 0.295 & 0.294 & & 0.497 & 0.503 \\
4 & 0.292 & 0.293 & & 0.495 & 0.499 \\
5 & 0.291 & 0.292 & 0.501 & 0.507 \\
6 & 0.294 & 0.295 & & 0.494 & 0.498 \\
7 & 0.293 & 0.293 & & 0.494 & 0.500 \\
8 & 0.292 & 0.293 & 0.501 & 0.506 \\
9 & 0.292 & 0.292 & 0.494 & 0.500 \\
10 & 0.294 & 0.294 & 0.499 & 0.505 \\
Average & 0.293 & 0.294 & 0.497 & 0.502 \\
\hline
\end{tabular}

${ }^{a}$ Model L2 is the linear animal model with covariance constrained to zero, and Model T2 is the threshold animal model with covariance constrained to zero. 
Table 4 Average, standard deviation (SD), minimum and maximum of correlation estimates between split data sets ${ }^{\mathrm{a}}$ for calving ease breeding values of sires with progeny ( $\mathrm{N}=3148$ ) from Model L2 and Model T2

\begin{tabular}{|c|c|c|c|c|c|c|c|c|}
\hline \multirow[b]{3}{*}{ Category $^{b}$} & \multicolumn{8}{|c|}{ Model L2 ${ }^{\mathrm{C}}$} \\
\hline & \multicolumn{4}{|c|}{ Direct genetic effect } & \multicolumn{4}{|c|}{ Maternal genetic effect } \\
\hline & Mean & SD & Min & Max & Mean & SD & Min & Max \\
\hline Sires $>0 \leq 50$ & 0.635 & 0.028 & 0.604 & 0.663 & 0.465 & 0.057 & 0.369 & 0.506 \\
\hline Sires $>50 \leq 100$ & 0.647 & 0.047 & 0.605 & 0.698 & 0.369 & 0.037 & 0.329 & 0.407 \\
\hline Sires $>100$ & \multicolumn{8}{|c|}{ Model T2 ${ }^{c}$} \\
\hline Sires $>0 \leq 50$ & 0.507 & 0.030 & 0.475 & 0.536 & 0.360 & 0.047 & 0.279 & 0.392 \\
\hline Sires $>50 \leq 100$ & 0.549 & 0.057 & 0.478 & 0.610 & 0.282 & 0.032 & 0.238 & 0.316 \\
\hline Sires $>100$ & 0.599 & 0.038 & 0.538 & 0.634 & 0.334 & 0.069 & 0.226 & 0.406 \\
\hline
\end{tabular}

an five paired data subsets.

${ }^{b}$ Sires $>0 \leq 50$ : sires with 50 or fewer progeny records in data file, sires $>50 \leq 100$ : sires with $51-100$ progeny records in data file, sires $>100$ : sires with more than 100 progeny records in data file.

${ }^{c}$ Model L2 is the linear animal model with covariance constrained to zero, and Model T2 is the threshold animal model with covariance constrained to zero.

differences in the ranking of sires might occur using the linear versus threshold model. For all groups of sires, greater correlations were observed with Model L2 than with Model T2 for direct and maternal genetic effects. On average, correlations from the linear model was 17 and $23 \%$ higher than from the threshold model for direct and maternal breeding values, respectively. Thus, the linear model appeared to have a higher stability for predicting breeding values of animals whose records were randomly set to missing. These results were not in line with those obtained in beef cattle by Ramirez-Valverde et al. (2001) who found a better stability with a threshold approach. As expected, lower accuracy was observed for maternal effects.

The most likely reasons for the linear model showing consistently better results could be due to the fact that in the threshold model, additional parameters (thresholds) needs to be estimated leading potentially to lower estimation accuracies, especially for animal models. The threshold model fitted slightly better and explained more variance; however, breeding values were less stable between paired subsets especially for maternal additive genetic effects.

Fitting herd $\times$ year effect as random can lead to biased estimates of breeding values (Visscher $\delta$ Goddard 1993). Phocas \& Laloë (2003) stated that when a non-random association exists between sires and contemporary groups, the correlation between true and predicted breeding values can be affected. However, it is unsure to what degree this non-random association has to exist to create this behaviour.
Spearman's rank correlations between sire breeding values from Model L2 and Model T2 were 0.972 and 0.971 for direct and maternal calving ease breeding values, respectively, indicating that the ranking of sires was nearly identical between the linear and the threshold models. This was in agreement with results from similar comparisons involving categorical traits in cattle (Weller et al. 1988; Clutter et al. 1989; Ramirez-Valverde et al. 2001) and in sheep (Olesen et al. 1994; Matos et al. 1997).

\section{Conclusions}

(Co)variance components and derived genetic parameters for calving ease were estimated with univariate linear and threshold animal models. The directmaternal genetic correlation was positive for the linear model and negative for the threshold model, but neither was significantly different from zero. The heritability estimates were consistent with those found in other studies on calving ease in dairy cattle. The threshold models showed a better goodness of fit than linear models. However, in terms of predictive ability, no clear advantage of the threshold models over the linear models was found with our data. Accordingly, it would be preferable and more technically feasible to use a linear model to perform genetic evaluation of calving ease. Thus, the linear animal model without covariance between direct and maternal additive genetic effects (i.e. Model L2) would be the model of choice to implement the routine genetic evaluation of calving ease for the Walloon dairy cattle. 


\section{Acknowledgements}

The Ministry of Agriculture of the Walloon Region of Belgium (Service Public de Wallonie, Direction générale opérationnelle “Agriculture, Ressources naturelles et Environnement) is acknowledged for its financial support. The authors gratefully acknowledge the technical support provided by the Walloon Breeding Association (Ciney, Belgium). Computational resources have been provided by the Consortium des Équipements de Calcul Intensif (CÉCI) funded by the Fund for Scientific Research (F.R.S.FNRS, Brussels, Belgium) under Grant No. 2.5020.11. The authors are grateful to the anonymous reviewers for their helpful suggestions and comments on the manuscript.

\section{References}

Canavesi F., Biffani S., Samoré A.B. (2003) Revising the genetic evaluation for calving ease in the Italian Holstein Friesian. Interbull Bull., 30, 82.

Clutter A.C., Berger P.J., Mattison J.M. (1989) Threshold model analysis of dystocia in dairy cattle when progeny information is limited. J. Dairy Sci., 72, 3264 3272.

Dekkers J.C.M. (1994) Optimal breeding strategies for calving ease. J. Dairy Sci., 77, 3441-3453.

Dematawena C.M.B., Berger P.J. (1997) Effect of dystocia on yield, fertility, and cow losses and an economic evaluation of dystocia scores for Holsteins. J. Dairy Sci., 80, 754-761.

Dempster E.R., Lerner I.M. (1950) Heritability of threshold characters. Genetics, 35, 212.

Ducrocq V. (2000) Calving ease evaluation of French dairy bulls with a heteroskedastic threshold model with direct and maternal effects. Interbull Bull., 25, 123.

Eaglen S.A.E., Coffey M.P., Woolliams J.A., Mrode R., Wall E. (2011) Phenotypic effects of calving ease on the subsequent fertility and milk production of dam and calf in UK Holstein-Friesian heifers. J. Dairy Sci., 94, 5413-5423.

Eaglen S.A.E., Coffey M.P., Woolliams J.A., Wall E. (2012) Evaluating alternate models to estimate genetic parameters of calving traits in United Kingdom Holstein-Friesian dairy cattle. Genet. Sel. Evol., 44, 1-13.

Gianola D. (1982) Theory and analysis of threshold characters. J. Anim. Sci., 54, 1079-1096.

Hoeschele I. (1988) Comparison of "Maximum A-Posteriori Estimation" and "Quasi Best Linear Unbiased Prediction" with threshold characters. J. Anim. Breed. Genet., 105, 337-361.

Interbull. 2013. Description of National Genetic Evaluations Systems for dairy cattle traits as applied in different Interbull member countries.
López de Maturana E.L., Legarra A., Varona L., Ugarte E. (2007a) Analysis of fertility and dystocia in holsteins using recursive models to handle censored and categorical data. J. Dairy Sci., 90, 2012-2024.

López de Maturana E.L., Ugarte E., González-Recio O. (2007b) Impact of calving ease on functional longevity and herd amortization costs in Basque Holsteins using survival analysis. J. Dairy Sci., 90, 4451-4457.

López de Maturana E.L., Gianola D., Rosa G.J.M., Weigel K.A. (2009) Predictive ability of models for calving difficulty in US Holsteins. J. Anim. Breed. Genet., 126, 179188.

Luo M.F., Boettcher P.J., Dekkers J.C.M., Schaeffer L.R. (1999) Bayesian analysis for estimation of genetic parameters of calving ease and stillbirth for Canadian Holsteins. J. Dairy Sci., 82, 1848-el.

Luo M.F., Boettcher P.J., Schaeffer L.R., Dekkers J.C.M. (2001) Bayesian inference for categorical traits with an application to variance component estimation. J. Dairy Sci., 84, 694-704.

Matos C.A., Thomas D.L., Gianola D., Perez-Enciso M., Young L.D. (1997) Genetic analysis of discrete reproductive traits in sheep using linear and nonlinear models: II. Goodness of fit and predictive ability. J. Anim. Sci., 75, 88-94.

Mee J.F. (2008) Prevalence and risk factors for dystocia in dairy cattle: a review. Vet. J., 176, 93-101.

Misztal I., Gianola D., Foulley J.L. (1989) Computing aspects of a nonlinear method of sire evaluation for categorical data. J. Dairy Sci., 72, 1557-1568.

Misztal I., Tsuruta S., Auvray B., Lee J.M. (2002) BLUPF90 and related programs (BGF90). In: Proc. 7th World Congr. Genet. Appl. Livest. Prod., Montpellier, France, pp. 743-744. Comm. No. 28-07.

Olesen I., Perez-Enciso M., Gianola D., Thomas D.L. (1994) A comparison of normal and nonnormal mixed models for number of lambs born in Norwegian sheep. $J$. Anim. Sci., 72, 1166-1173.

Phocas F., Laloë D. (2003) Evaluation models and genetic parameters for calving difficulty in beef cattle. J. Anim. Sci., 81, 933-938.

Ramirez-Valverde R., Misztal I., Bertrand J.K. (2001) Comparison of threshold vs linear and animal vs sire models for predicting direct and maternal genetic effects on calving difficulty in beef cattle. J. Anim. Sci., 79, 333338 .

Steinbock L., Näsholm A., Berglund B., Johansson K., Philipsson J. (2003) Genetic effects on stillbirth and calving difficulty in Swedish Holsteins at first and second calving. J. Dairy Sci., 86, 2228-2235.

Varona L., Misztal I., Bertrand J.K. (1999) Threshold-linear versus linear-linear analysis of birth weight and calving ease using an animal model: II. Comparison of models. J. Anim. Sci., 77, 2003-2007. 
Visscher P.M., Goddard M.E. (1993) Fixed and random contemporary groups. J. Dairy Sci., 76, 1444-1454.

Wang C.S., Quaas R.L., Pollak E.J. (1997) Bayesian analysis of calving ease scores and birth weights. Genet. Sel. Evol., 29, 117.

Weller J.I., Gianola D. (1989) Models for genetic analysis of dystocia and calf mortality. J. Dairy Sci., 72, 26332643.
Weller J.I., Misztal I., Gianola D. (1988) Genetic analysis of dystocia and calf mortality in Israeli-Holsteins by threshold and linear models. J. Dairy Sci., 71, 24912501.

Wiggans G.R., Misztal I., Van Tassell C.P. (2003) Calving ease (co)variance components for a sire-maternal grandsire threshold model. J. Dairy Sci., 86, 1845-1848. 